Sharif University of Technology
Scientia Iranica
Transactions E: Industrial Engineering
hCIttp://scientiairanica.sharif.edu
IRAN ICA

\title{
A bi-objective multi-echelon supply chain model with Pareto optimal points evaluation for perishable products under uncertainty
}

\author{
H. Gitinavard, S.H. Ghodsypour, and M. Akbarpour Shirazi* \\ Department of Industrial Engineering and Management Systems, Amirkabir University of Technology, 424 Hafez Ave., Tehran, Iran.
}

Received 21 August 2017; received in revised form 8 March 2018; accepted 21 July 2018

\author{
KEYWORDS \\ Multi-echelon supply \\ chain; \\ Pareto optimal \\ solution; \\ Perishable products; \\ Group decision \\ analysis; \\ Possibilistic approach.
}

\begin{abstract}
Selecting the most suitable optimal point among Pareto optimal points could help experts make an appropriate decision in an uncertain and complex situation. In this paper, an evaluation and ranking approach is proposed based on a hesitant fuzzy set environment to assess the Pareto optimal points obtained through the proposed biobjective multi-echelon supply chain model by locating distribution centers. In this respect, the proposed model has been utilized for perishable products based on fuzzy customers' demand. To address this issue, the possibilistic chance-constrained programming approach has been utilized based on the trapezoidal fuzzy membership function. Moreover, the proposed hesitant fuzzy ranking approach is constructed based on group decision analysis and the last aggregation approach. Thereby, the last aggregation approach by aggregating the experts' opinions in the last step could prevent the data loss. However, a case study about the perishable dairy products is considered to indicate the applicability of the proposed bi-objective multi-echelon supply chain model by locating distribution centers. Finally, a comparative analysis is provided between the obtained results and the current practice to show the feasibility and efficiency of the proposed approach.
\end{abstract}

(C) 2019 Sharif University of Technology. All rights reserved.

\section{Introduction}

Selecting the most suitable optimal solution among the obtained Pareto optimal points, in multi-objective mathematical models, might be difficult for expert decision-makers in a complex and uncertain situation. To address this issue, selecting an appropriate tool could play the main role in helping the experts. In this respect, the Multi-Attribute Decision-Making (MADM) approaches are known to be suitable in

\footnotetext{
*. Corresponding author. Tel.: +982164545370; Fax: +982166413025

E-mail address: akbarpour@aut.ac.ir (M. Akbarpour Shirazi)
}

doi: $10.24200 /$ sci.2018.5047.1060 the literature for evaluating and ranking the selection problems under discrete space solution. The MADM methods are implemented to assess solutions to a wide range of social, economic, and management- and engineering-related problems [1-3].

Accordingly, in the real-world applications, the decision-making problems can be considered as indefinite and uncertain values, which were accorded as a complicated decision-making analysis procedure. Therefore, the decision-making analysis procedure can be used under fuzzy environment, where input parameters and the information are imprecise and uncertain to deal with such decision-making problems in the experts' evaluations [4]. In this regard, Zadeh's fuzzy set theory [5] and its extensions, such as type-2 fuzzy sets $[6,7]$, interval-valued fuzzy sets $[8,9]$, intuitionistic fuzzy sets [10], fuzzy multisets [6], and hesitant fuzzy 
sets $[11,12]$, have received much attention over the last decades.

Hence, the hesitant fuzzy set theory can help experts with the expression of some membership degrees in a set subject to margin of the errors. Based on hesitant fuzzy setting information, many authors have focused on decision-making problems to solve the selection problems. Zhang and Wei [13] developed VIKOR and TOPSIS methods under a hesitant fuzzy set environment to solve the decision-making problems. $\mathrm{Xu}$ and Zhang [14] extended the TOPSIS method based on hesitant fuzzy and interval-valued hesitant fuzzy sets with incomplete weight information. Wei and Zhang [15] presented a hesitant fuzzy multiple criteria decision-making method based on Shapley valued and VIKOR method. To handle the group decision-making problems, Chen and $\mathrm{Xu}$ [16] proposed a hesitant fuzzy ELECTRE II method. Joshi and Kumar [17] developed the TOPSIS method based on the proposed intervalvalued intuitionistic hesitant fuzzy Choquet integral operator to construct the group decision-making framework. Qin et al. [18] proposed an interval type2 fuzzy TODIM technique to solve group decisionmaking problems. However, in this paper, a novel hesitant fuzzy ranking approach was developed based on the last aggregation approach and the risk preferences of decision-makers. The last aggregation approach facilitated by aggregating the experts' judgments in the last step could prevent data loss.

However, ranking the Pareto optimal points, which were obtained through a multi-objective model, could be considered as a decision-making problem. Moreover, the multi-objective models are so sensitive in the current complex real world in many fields such as vehicle routing problems, supply chain management, distribution center location problems, etc. In the recent decade, many authors have proposed a multi-objective mathematical programming model by focusing on the multi-echelon supply chain problems as an interesting field.

In this respect, Ghodratnama et al. [19] presented a fuzzy possibilistic bi-objective mathematical programming model with the aim of minimizing the total costs. Mohammadi et al. [20] developed a new multiobjective multi-mode transportation model in order to minimize current investment costs and maximum transportation time based on stochastic parameters. Rahimi et al. [21] elaborated a bi-objective inventory routing model for perishable products to minimize the total inventory and distribution costs and maximize the customer satisfaction level. Ebrahimi Zade et al. [22] presented a non-linear multi-objective programming model for single and multiple allocations to solve the hub maximal covering problem. Pasandideh et al. [23] as well as Pasandideh et al. [24] presented a multiproduct multi-period three-echelon supply chain model based on uncertain situations. Khalili-Damghani et al. [25] proposed a novel bi-objective location-routing mathematical programming model for the distribution of perishable products to reduce the total costs and balance the distribution centers workload. Sarrafha et al. [26] used an optimization model for multi-echelon supply chain network design with respect to procurement, production, and distribution fields. Alavidoost et al. [27] applied a bi-objective mixed integer nonlinear programming model for multi-commodity triechelon supply chain networks to determine the optimum service level.

Ghodratnama et al. [28] proposed a novel multiobjective hub location and allocation model based on a multi-echelon supply chain overview. In their study, the robust and fuzzy goal programming approaches were tailored to solve the presented model. Pasandideh et al. [29] prepared a bi-objective mixed integer programming model with the aim of maximizing the weighted network reliability and the total flow based on considering the second type of coverage and timedependent reliability. Maghsoudlou et al. [30] presented a bi-objective optimization model for a threeechelon multi-server supply chain problem regarding cross-docking problem in congested systems. Ghezavati and Beigi [31] proposed a bi-objective mathematical model for a multi-echelon reverse logistics problem regarding the locating and routing approaches. Ebrahimi [32] proposed a bi-objective mixed-integer non-linear programming model to maximize customer satisfaction and, also, efficiency of the network. HabibiKouchaksaraei et al. [33] presented a robust optimization model for designing a bi-objective multi-period blood supply chain network in disaster with the aim of minimizing costs and shortage of blood.

The survey of the literature on the multi-echelon supply chain problems showed that a few studies have focused on perishable products. Consequently, this study presents a novel possibilistic non-linear biobjective multi-echelon supply chain model by locating distribution centers for perishable products so as to minimize the total costs and minimize the amount of backorder for important customers. In addition, some unique features were tailored to develop the proposed model as time windows, the perished rates, and warehouse considerations and prioritize the customers and candidate customers for the located distribution centers. Moreover, the possibilistic chance-constrained programming approach was provided to cope with existing uncertainty in the proposed mathematical model.

The rest of this paper is organized as follows: in Section 2, the proposed mixed-integer programming model for the distribution center location problem is presented. Then, a novel evaluation method based on group decision analysis and fuzzy environment is proposed to rank the obtained Pareto optimal solution. 


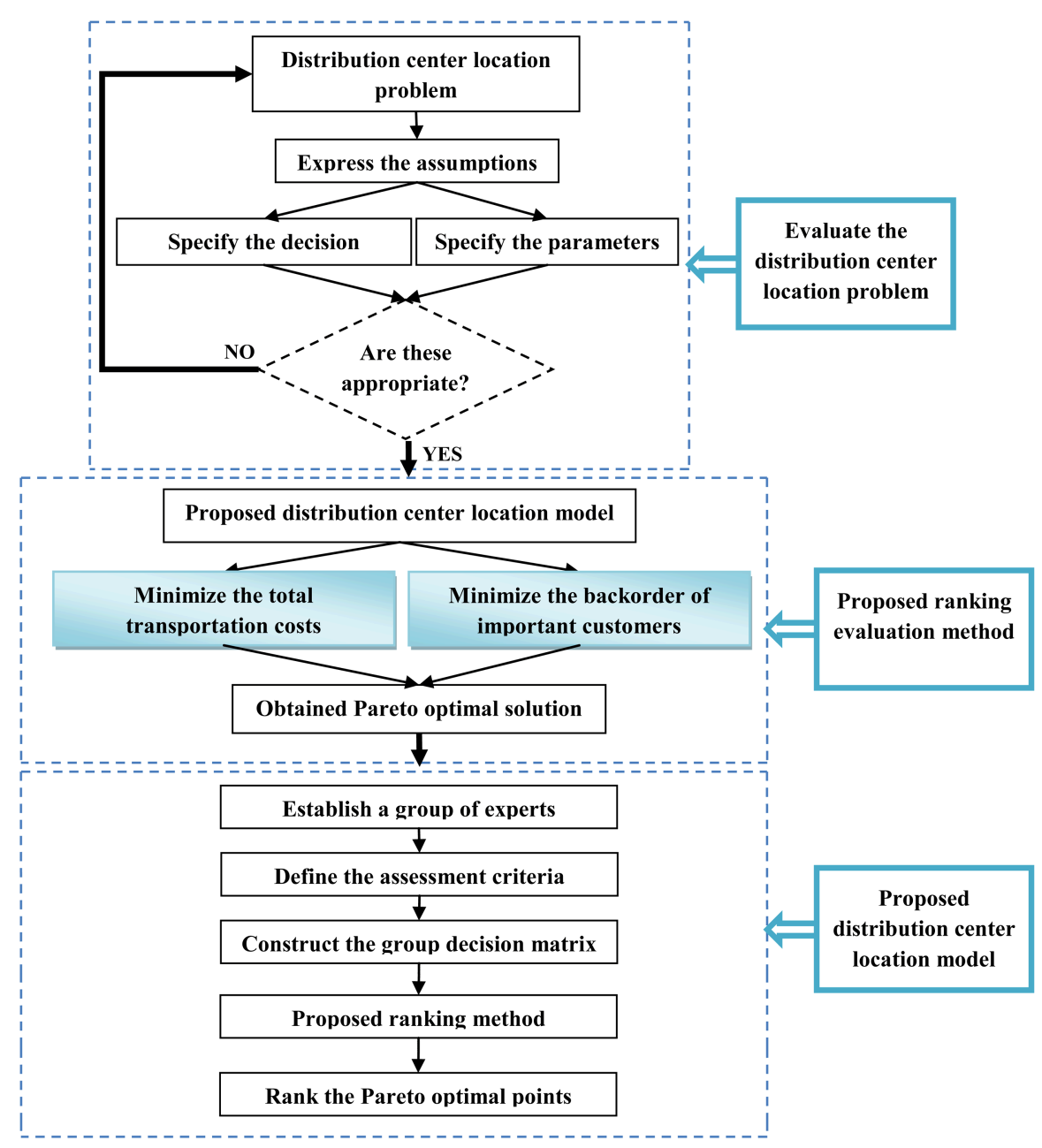

Figure 1. The hierarchical structure of the proposed approach.

In Section 3, the chance-constrained programming technique is considered to deal with involved uncertain parameters. In Section 4, a case study is provided to implement the proposed approach. In addition, the discussion about the presented approach is elaborated in Section 5. Finally, in Section 6, some concluding remarks and future directions are expressed.

\section{The proposed model}

The distribution of perishable products requires an appropriate system with respect to production planning, storing, and delivering [34]. In this study, a novel non-linear mixed integer programming model is developed to solve the distribution center location problem regarding the time windows of distribution center and customers for perishable products. Then, a novel ranking and evaluation method is presented under uncertainty to sort the obtained Pareto optimal solution. In this section, the distribution center location problem is described in detail, and the proposed model is presented based on some assumptions and notations. Then, the proposed ranking and evaluation method is provided. In this regard, the hierarchical structure of this study is depicted in Figure 1 for the convenient description of the proposed approach.

\subsection{Problem description}

As represented in Figure 2, the structure of the distribution center location problem, considered in this study, is depicted. Hence, $N$ customer and $F$ factory were considered to establish the network under study. In addition, each of $N$ customers was a potential candidate for determining the location of the distribution centers. The demands of each cus tomer $\left(d_{i p}^{t}\right)$ were settled at the beginning of each period and based on the customers' demands, and the located distribution centers ordered the products for the factories $\left(\vartheta_{j f p}^{t}\right)$. Regarding the occupied capacity $\left(\tau_{p}\right)$ parameter, meanwhile, the inventory level $\left(I_{j p}^{t}\right)$ should be managed based on the limited capacity of the located distribution centers $\left(\theta_{j}\right)$. In addition, the backorder level was determined based on the perished rate of transporting products from the factory to the 


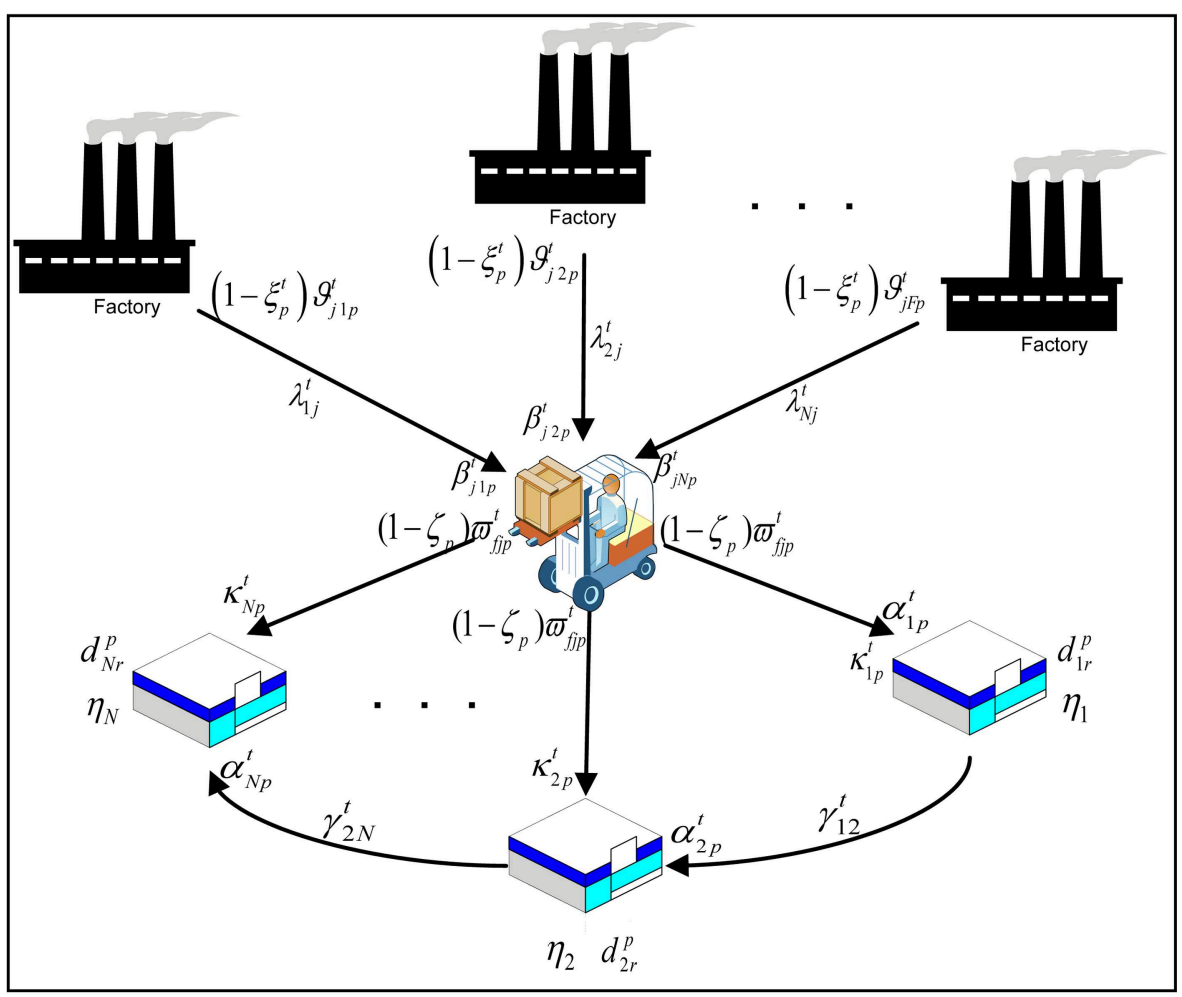

Figure 2. The schematic diagram of the distribution center location problem.

located distribution centers $\left(\xi_{p}^{t}\right)$ and from the located distribution centers to the customers $\left(\xi_{p}\right)$, which led to backorder levels from the factory $\left(b f_{f p}^{t}\right)$ and from the located distribution centers $\left(b c_{j p}^{t}\right)$. Therefore, the number of the products delivered to both located distribution centers $\left(\varpi_{f j p}^{t}\right)$ and the customers $\left(\kappa_{j i p}^{t}\right)$ was specified based on the afore-mentioned backorder level, respectively. Hence, a specific time window was defined for each located distribution center $\left(\left[\varphi_{j p}^{l t}, \varphi_{j p}^{l t}\right]\right)$ and customer $\left(\left[\omega_{i p}^{l t}, \omega_{i p}^{l t}\right]\right)$ to receive their required products at an appropriate delivery time from factories to the located distribution centers $\left(\beta_{j f p}^{t}\right)$ and from the located distribution centers to customers $\left(\alpha_{\text {jip }}^{t}\right)$. In this regard, delivery time from factories to the located distribution centers depends on the transportation time between them $\left(\lambda_{f j}^{t}\right)$, and also the delivery time from the located distribution centers to the customers is dependent on the transportation time $\left(\gamma_{i j}^{t}\right)$ and the service rate of each customer $\left(S_{i}^{p}\right)$. However, the distribution center location problem regarding the perishable consideration was manipulated with the aim of minimizing the total costs and the amount of backorder for important customers $\left(\eta_{i}^{C}\right)$ and candidate customers for the distribution center location $\left(\eta_{j}^{H}\right)$.

\subsection{Assumptions}

To extend the proposed distribution center location model, the following assumptions are provided:
1. The demand of each customer is uncertain;

2. The transportation routes are known;

3. A time window is considered for each customer and the located distribution center;

4. The relative significance of each customer is related to the amount and frequency of the purchases;

5. The distribution system has one located distribution center, which collects the demand of customers from some factories;

6. The inventory and backorder level are allowed, both of which should be zero at the end of the planning horizon;

7. The demand of each customer in each period is determined based on the historical data and the experts' judgments;

8. The located distribution centers' orders are provided at the beginning of the horizon planning regarding the imprecise demand;

9. The features of the distribution center location problem include network solution domain, minisum criteria, and the exogenous source of determining the number of the distribution centers to locate capacitated and multiple allocations;

10. The capacity of vehicles is supposed to be infinite. 


\subsection{Notations}

The indices, parameters, and decision variables of the considered distribution center location problem are defined in this section.

$$
\begin{array}{ll}
\text { Indices } & \\
i, j & \text { Index of customers }(i, j, l=1, \cdots, N) \\
f & \text { Index of factories }(f=1,2, \cdots, F) \\
p & \begin{array}{l}
\text { Index of perishable products } \\
(p=1,2, \cdots, P)
\end{array} \\
t & \text { Index of time periods }(t=1,2, \cdots, T)
\end{array}
$$

\section{Parameters}

$d_{i p}^{t} \quad$ Demand of customer $i$ for product $p$ in period $t$

$\lambda_{f j}^{t} \quad$ Transportation time between factory $f$ and located distribution center $j$ in period $t$

$\gamma_{i j}^{t} \quad$ Transportation time between customers $i$ and $j$ in period $t$

$S_{i}^{p} \quad$ The service rate of customer $i$ for product $p$

$\theta_{j} \quad$ The capacity of located distribution center $j$

$\tau_{p} \quad$ The occupied capacity by a unit of product $p$

$\omega_{i p}^{l t} \quad$ The lower bound of time window for customer $i$ of product $p$ in period $t$

$\omega_{i p}^{u t} \quad$ The upper bound of time window for customer $i$ of product $p$ in period $t$

$\eta_{i}^{C} \quad$ The relative significance of customer $i$

$\eta_{j}^{H} \quad$ The relative significance of candidate customer $j$ for a distribution center location

$\zeta_{p} \quad$ The perished rate of product $p$ in period $t$ at located distribution centers

$\xi_{p}^{t} \quad$ The perished rate of product $p$ in period $t$ during transportation from a factory to located distribution centers

$\varphi_{j p}^{l t} \quad$ The lower bound of time window for located distribution center $j$ of product $p$ in period $t$

$\varphi_{j p}^{u t} \quad$ The upper bound of time window for located distribution center $j$ of product $p$ in period $t$

$C_{j i p} \quad$ The transportation cost of located distribution center $j$ to customer $i$ per product $p$

$C F_{f j p}^{t} \quad$ The transportation cost of factory $f$ to located distribution center $j$ per product $p$ in period $t$
$C F_{j} \quad$ The fixed cost of establishing distribution center $j$

$C I_{j p}^{t} \quad$ The holding cost of located distribution center $j$ per product $p$ in period $t$

\section{Decision variables}

$x_{i j} \quad 1$ if customer $i$ is allocated to located distribution center $j$

$y_{f j} \quad 1$ if factory $f$ to allocated to the located distribution center $j$

$\alpha_{j i p}^{t} \quad$ The delivery time of product $p$ to customer $i$ from located distribution center $j$ in period $t$

$d t c_{j i}^{t} \quad$ Departure time from located distribution center $j$ to customer $i$ in period $t$

$\beta_{f j p}^{t} \quad$ The delivery time of product $p$ from factory $f$ to located distribution center $j$ in period $t$

$d t f_{f j}^{t} \quad$ Departure time from factory $f$ to located distribution center $j$ in period $t$

$\vartheta_{j f p}^{t} \quad$ The number of ordered products $p$ from located distribution center $j$ to factory $f$ in period $t$

$\varpi_{f j p}^{t} \quad$ The number of delivered products $p$ to the located distribution center $j$ from factory $f$ in period $t$

$\kappa_{j i p}^{t} \quad$ The number of delivered products $p$ to customer $i$ from located distribution center $j$ in period $t$

$I_{j p}^{t} \quad$ The inventory level of product $p$ from located distribution center $j$ in period $t$

$b c_{j p}^{t} \quad$ The backorder level of product $p$ from located distribution center $j$ in period $t$

$b f_{f p}^{t} \quad$ The backorder level of product $p$ from factory $f$ in period $t$

\subsection{The proposed model}

The novel non-linear mixed integer programming model for the distribution center location problem is proposed as follows:

\section{A.1:}

$$
\begin{aligned}
Z_{1}= & \min \sum_{t=1}^{T} \sum_{p=1}^{P} \sum_{f=1}^{F} \sum_{j=1}^{N} y_{f j} \varpi_{f j p}^{t} C F_{f j p}^{t} \\
& +\sum_{t=1}^{T} \sum_{p=1}^{P} \sum_{i=1}^{N} \sum_{j=1}^{N} x_{i j} \kappa_{j i p}^{t} C_{j i p} \\
& +\sum_{t=1}^{T} \sum_{j=1}^{N} \sum_{p=1}^{P} C I_{j p}^{t} I_{j p}^{t}+\sum_{j=1}^{N} x_{j j} C F_{j},
\end{aligned}
$$




$$
\begin{aligned}
Z_{2}= & \min \sum_{t=1}^{T} \sum_{p=1}^{P} \sum_{i=1}^{N} \sum_{j=1}^{N} \eta_{i}^{C}\left(d_{i p}^{t}-x_{i j} \kappa_{j i p}^{t}\right) \\
& +\sum_{t=1}^{T} \sum_{p=1}^{P} \sum_{f=1}^{F} \sum_{j=1}^{N} \eta_{j}^{H}\left(x_{j j} \vartheta_{j f p}^{t}-y_{f j} \varpi_{f j p}^{t}\right),
\end{aligned}
$$

$\sum_{j=1}^{N} x_{j j}=R$

$$
\begin{array}{ll}
x_{i j} \leq x_{j j} & \forall i, j, \\
y_{f j} \leq x_{j j} & \forall f, j, \\
\alpha_{j i p}^{t}=\left(d t c_{j i}^{t}+\gamma_{i j}^{t}+S_{i}^{p} \kappa_{j i p}^{t}\right) x_{i j} & \forall i, j, p, t, \\
\beta_{f j p}^{t}=y_{f j}\left(\lambda_{f j}^{t}+d t f_{f j}^{t}\right) & \forall j, f, p, t, \\
x_{i j} \omega_{i p}^{l t} \leq \alpha_{j i p}^{t} \leq x_{i j} \omega_{i p}^{u t} & \forall j \neq i, p, t, \\
y_{f j} \varphi_{j p}^{l t} \leq \beta_{f j p}^{t} \leq y_{f j} \varphi_{j p}^{u t} & \forall j, f, p, t, \\
\sum_{i=1}^{N} d_{i p}^{t} \leq \sum_{j=1}^{N} \sum_{f=1}^{F} \vartheta_{j f p}^{t} x_{j j} & \forall p, t,
\end{array}
$$$$
\sum_{i=1}^{N} \kappa_{j i p}^{t}+b c_{j p}^{t-1}=\sum_{i=1}^{N} d_{i p}^{t}+I_{j p}^{t} \quad \forall j, p, t,
$$$$
\sum_{f=1}^{F} \sum_{p=1}^{P} \tau_{p} \varpi_{f j p}^{t} y_{f j} \leq \theta_{j} x_{j j} \quad \forall j, t
$$$$
\sum_{f=1}^{F} \sum_{j=1}^{N} \varpi_{f j p}^{t} y_{f j}=\left(1-\xi_{p}^{t}\right) \sum_{j=1}^{N} \sum_{f=1}^{F} \vartheta_{j f p}^{t} x_{j j}
$$$$
\forall p, t
$$$$
\sum_{j=1}^{N} \sum_{i=1}^{N} \kappa_{j i p}^{t} x_{i j}=\left(1-\zeta_{p}\right) \sum_{f=1}^{F} \sum_{j=1}^{N} \varpi_{f j p}^{t} y_{f j}
$$

$$
\forall p, t
$$$$
\sum_{f=1}^{F} \vartheta_{j f p}^{t}+b c_{j p}^{t-1}=\sum_{f=1}^{F} \varpi_{f j p}^{t}+I_{j p}^{t}+\sum_{f=1}^{F} b f_{f p}^{t-1}
$$$$
\forall j, p, t,
$$$$
b f_{f p}^{t}=b c_{j p}^{t}=I_{j p}^{t}=0 \quad \forall f, j, p
$$

$$
\begin{aligned}
& \sum_{f=1}^{F} \varpi_{f j p}^{t} y_{f j} \leq \sum_{f=1}^{F} \vartheta_{j f p}^{t} x_{j j} \\
& \quad+\sum_{t^{\prime}=1}^{T^{\prime}} \sum_{f=1}^{F}\left(\vartheta_{j f p}^{t^{\prime}-1} x_{j j}-\varpi_{f j p}^{t^{\prime}-1} x_{f j}\right)
\end{aligned}
$$$$
\forall j, i, p, t \geq 2 \text {, }
$$

$$
\begin{aligned}
& \sum_{f=1}^{F} \varpi_{f j p}^{1} y_{f j} \leq \sum_{f=1}^{F} \vartheta_{j f p}^{1} x_{j j} \quad \forall j, i, p \\
& \sum_{j=1}^{N} \kappa_{j i p}^{t} x_{i j} \leq d_{i p}^{t}+\left(\sum_{t^{\prime}=1}^{T^{\prime}} d_{i p}^{t^{\prime}-1}-\sum_{t^{\prime}=1}^{T^{\prime}} \sum_{j=1}^{N} \kappa_{j i p}^{t^{\prime}-1} x_{i j}\right)
\end{aligned}
$$

$$
\forall i, p, t \geq 2
$$

$$
\sum_{j=1}^{N} \kappa_{j i p}^{1} x_{i j} \leq d_{i p}^{1} \quad \forall i, p
$$

$$
\begin{array}{ll}
\sum_{f=1}^{F} \sum_{t=1}^{T} \varpi_{f j p}^{t}=\sum_{f=1}^{F} \sum_{t=1}^{T} \vartheta_{j f p}^{t} & \forall j, p, \\
\sum_{i=1}^{N} \sum_{t=1}^{T} \kappa_{j i p}^{t}=\sum_{i=1}^{N} \sum_{t=1}^{T} d_{i p}^{t} & \forall j, p, \\
x_{i j}, y_{f j} \in\{0,1\} & \forall i, j, f, \\
\varpi_{f j p}^{t}, \kappa_{j i p}^{t}, \vartheta_{j f p}^{t}, \alpha_{j i p}^{t}, d t c_{f j}^{t}, \beta_{f j p}^{t}, d t f_{f j}^{t}, I_{j p}^{t}, \\
b c_{j p}^{t}, b f_{f p}^{t} \geq 0 & \forall i, j, f, p, t .
\end{array}
$$

Aimed at minimizing the total cost, the first objective function was established. The first part of the objective function concerns the transportation cost of the factory to the located distribution centers; the second, third, and fourth parts of the objective function concern the transportation cost of the located distribution centers to the customers, the holding cost, and the fixed cost of establishing a distribution center, respectively. The second objective function minimizes the deviation of delivered products for important customers and candidate customers regarding their demands for increasing their satisfaction.

In addition, Constraint (3) guarantees that $R$ distribution centers must be located. Constraints (4) and (5) determine that all nodes of customers and factories must be allocated to located distribution centers. Constraints (6) and (7) determine the delivery time of each product to customers and located distribution centers, respectively. Constraints (8) and (9) specify the time windows, in which customers and located 
distribution centers require to receive products. Constraint (10) expresses that the number of the ordered products must be lower than the customers' demands. Constraint (11) is the balanced equation for the located distribution centers. Constraint (12) determines the limited capacity of the located distribution centers. Constraints (13) and (14) represent the number of the products delivered to the located distribution centers and the customers, respectively. Constraint (15) is a balanced relationship between the factories and the located distribution centers. Constraint (16) ensures that, at the end of the horizon planning, the backorder from the located distribution centers, factories, and the inventory level of located distribution centers must be zero. Constraints (17) and (18) guarantee that delivery of extra products to the located distribution centers is not allowed. Constraints (19) and (20) ensure that delivery of extra products to each customer is not allowed. Constraints (21) and (22) guarantee that all the ordered products and customers' demands must be satisfied during the horizon planning. Finally, Constraints (23) and (24) determine the binary and integer variables, respectively.

\subsection{Ranking and evaluating method}

A committee of decision-makers $\left(E_{k}, k=1,2, \cdots, K\right)$ is established to evaluate the candidates Pareto set $\left(P_{i}, i=1,2, \cdots, m\right)$ under the conflicted criteria $\left(C_{j}, j=1,2, \cdots, n\right)$. To address the issue, decisionmakers could assign their present opinions to rate the candidates' Pareto sets and the relative importance of criteria based on linguistic variables, which are represented in Tables 1 and 2, respectively.

As indicated in Tables 1 and 2, the risk preference of each decision-maker is considered in the procedure of the evaluation approach to obtain a precise solution. However, a novel ranking and evaluation method is prepared in the following steps to determine the best Pareto optimal point based on the preferred judgments of experts:

Table 1. Linguistic variable for rating the candidates Pareto set.

\begin{tabular}{lcccc}
\hline \multirow{2}{*}{ Linguistic variable } & $\begin{array}{c}\text { Interval-valued } \\
\text { hesitant fuzzy element }\end{array}$ & \multicolumn{2}{c}{ Decision-maker's risk preferences } \\
\cline { 3 - 5 } & {$[1.00,1.00]$} & 1 & 1 & 1 \\
\hline Extremely Good (EG) & {$[0.90,0.90]$} & 0.90 & 0.90 & 0.90 \\
Very Good (VVG) & {$[0.80,0.90]$} & 0.80 & 0.85 & 0.90 \\
Very Good (VG) & {$[0.70,0.80]$} & 0.70 & 0.75 & 0.80 \\
Good (G) & {$[0.60,0.70]$} & 0.60 & 0.65 & 0.70 \\
Moderately Good (MG) & {$[0.50,0.60]$} & 0.50 & 0.55 & 0.60 \\
Moderate (M) & {$[0.40,0.50]$} & 0.40 & 0.45 & 0.50 \\
Moderately Poor (MP) & {$[0.25,0.40]$} & 0.25 & 0.325 & 0.40 \\
Poor (P) & {$[0.10,0.25]$} & 0.10 & 0.175 & 0.25 \\
Very Poor (VP) & {$[0.10,0.10]$} & 0.10 & 0.10 & 0.10 \\
\hline Very Very Poor (VVP) & & & & Moderate \\
\hline
\end{tabular}

Table 2. Linguistic variable for specifying the relative importance of criteria.

\begin{tabular}{lcccc}
\hline \multirow{2}{*}{ Ling uistic variable } & $\begin{array}{c}\text { Interval-valued } \\
\text { hesitant fuzzy element }\end{array}$ & \multicolumn{2}{c}{ Decision-maker's risk preferences } \\
\cline { 3 - 5 } & {$[0.90,0.90]$} & 0.90 & 0.90 & 0.90 \\
\hline Very High (VH) & {$[0.75,0.80]$} & 0.75 & 0.775 & 0.80 \\
High (H) & {$[0.50,0.55]$} & 0.50 & 0.525 & 0.55 \\
Medium (M) & {$[0.35,0.40]$} & 0.35 & 0.375 & 0.40 \\
Low (L) & {$[0.10,0.10]$} & 0.10 & 0.10 & 0.10 \\
Very Low (VL) & & & & Moderate \\
\hline
\end{tabular}




\begin{tabular}{c}
$C_{1}$ \\
$\Im=P_{2}\left[\begin{array}{cccc|}\hline & C_{2} & \cdots & C_{n} \\
\left\{\mu_{11}^{1}, \mu_{11}^{2}, \cdots, \mu_{11}^{k}\right\} & \left\{\mu_{12}^{1}, \mu_{12}^{2}, \cdots, \mu_{12}^{k}\right\} & \cdots & \left\{\mu_{1 n}^{1}, \mu_{1 n}^{2}, \cdots, \mu_{1 n}^{k}\right\} \\
\vdots & \left\{\mu_{22}^{1}, \mu_{22}^{2}, \cdots, \mu_{2}^{k}\right\} & \cdots & \left\{\mu_{2 n}^{1}, \mu_{2 n}^{2}, \cdots, \mu_{2 n}^{k}\right\} \\
& \vdots & \ddots & \vdots \\
\left\{\mu_{m 1}^{1}, \mu_{m 1}^{2}, \cdots, \mu_{m 1}^{k}\right\} & \left\{\mu_{m 2}^{1}, \mu_{m 2}^{2}, \cdots, \mu_{m 2}^{k}\right\} & \cdots & \left\{\mu_{m n}^{1}, \mu_{m n}^{2}, \cdots, \mu_{m n}^{k}\right\}\end{array}\right]_{m \times n}$ \\
\hline
\end{tabular}

\section{Box I}

Step 1. Determine the hesitant fuzzy group decision matrix $(\Im)$ based on decision-makers' opinions by Eq. (25) as shown in Box I.

Step 2. Normalize the hesitant fuzzy group decision matrix based on the following relation:

$$
\begin{gathered}
b_{i j}=\cup_{t_{i j} \in b_{i j}}= \begin{cases}\left\{\mu_{i j}\right\} & \text { for positive criteria } \\
\left\{1-\mu_{i j}\right\} & \text { for negative criteria }\end{cases} \\
\forall i=1, \cdots, m ; \quad j=1, \cdots, n .
\end{gathered}
$$

Step 3. Establish the normalized hesitant fuzzy group decision matrix for each candidate $\left(\Im_{i}^{N}\right)$ as follows:

$$
\Im_{i}^{N}=E_{2}\left(\begin{array}{cccc}
C_{1} & C_{2} & \cdots & C_{n} \\
\mu_{i 1}^{1} & \mu_{i 2}^{1} & \cdots & \mu_{i n}^{1} \\
\mu_{i 1}^{2} & \mu_{i 2}^{2} & \ldots & \mu_{i n}^{2} \\
\vdots & \vdots & \ddots & \vdots \\
\mu_{i 1}^{k} & \mu_{i 2}^{k} & \cdots & \mu_{i n}^{k}
\end{array}\right)_{k \times n}
$$

Step 4. Determine the final criteria weights based on the hesitant fuzzy geometric operator [35] as follows:

$$
\begin{aligned}
\omega_{j} & =H F G\left(\varpi_{j}^{1}, \varpi_{j}^{2}, \cdots, \varpi_{j}^{k}\right)=\otimes_{k=1}^{K}\left(\varpi_{j}^{k}\right)^{\frac{1}{K}} \\
& =\prod_{k=1}^{K}\left(\varpi_{j}^{k}\right)^{\frac{1}{K}} \quad \forall j,
\end{aligned}
$$

where $\varpi_{j}^{k}$ represents the opinions of the $k$ th decisionmaker for the $j$ th criterion.

Step 5. Construct the weighted normalized hesitant fuzzy group decision matrix for each candidate $\left(\Im_{i}^{W N}\right)$ based on criteria weights, which are determined by decision-makers' opinions.

$$
\begin{aligned}
& \begin{array}{llll}
C_{1} & C_{2} & \cdots & C_{n}
\end{array} \\
& \Im_{i}^{W N}=E_{2}\left(\begin{array}{cccc}
E_{1} \mu_{i 1}^{1} & \omega_{2} \mu_{i 2}^{1} & \ldots & \omega_{n} \mu_{i n}^{1} \\
\omega_{1} \mu_{i 1}^{2} & \omega_{2} \mu_{i 2}^{2} & \ldots & \omega_{n} \mu_{i n}^{2} \\
\vdots & \vdots & \ddots & \vdots \\
\omega_{1} \mu_{i 1}^{k} & \omega_{2} \mu_{i 2}^{k} & \ldots & \omega_{n} \mu_{i n}^{k}
\end{array}\right)_{k \times n}
\end{aligned}
$$

$\forall i$

where $\omega_{j}(j=1,2, \cdots, n)$ is the relative importance of each criterion and $\sum_{j=1}^{n} \omega_{j}=1$.

Step 6. Determine the hesitant fuzzy positive ideal decision matrix $\left(\wp^{*}\right)$ based on the following relations:

$$
\wp^{*}=E_{1} E_{2}\left(\begin{array}{cccc}
\mu_{1}^{* 1} & \mu_{2}^{* 1} & \cdots & \mu_{n}^{* 1} \\
\mu_{1}^{* 2} & \mu_{2}^{* 2} & \cdots & \mu_{n}^{* 2} \\
\vdots & \vdots & \ddots & \vdots \\
\mu_{k}^{* k} & \mu_{2}^{* k} & \cdots & \mu_{n}^{* k}
\end{array}\right)_{k \times n}
$$

where $\mu_{j}^{* k}=\frac{1}{m} \sum_{i=1}^{m} \mu_{i j}^{k} \forall j, k$. The positive ideal decision should be made based on the average of individual preferences of decision-makers' judgments in closeness to the real world [36].

Step 7. Specify the hesitant fuzzy negative ideal solution, including two parts as hesitant fuzzy left negative ideal decision matrix $\left(\zeta_{p}^{\ell-}\right)$ and the hesitant fuzzy right negative ideal decision matrix $\left(\zeta_{p}^{R-}\right)$, based on the following relations: 


$$
\begin{aligned}
& \begin{array}{llll}
C_{1} & C_{2} & \cdots & C_{n}
\end{array} \\
& \wp^{-\ell}=E_{2}\left(\begin{array}{cccc}
\mu_{1}^{-\ell 1} & \mu_{2}^{-\ell 1} & \cdots & \mu_{n}^{-\ell 1} \\
\mu_{1}^{-\ell 2} & \mu_{2}^{-\ell 2} & \cdots & \mu_{n}^{-\ell 2} \\
\vdots & \vdots & \ddots & \vdots \\
\mu_{1}^{-\ell k} & \mu_{2}^{-\ell k} & \cdots & \mu_{n}^{-\ell k}
\end{array}\right)_{k \times n} \\
& \mu_{j}^{-\ell k}=\min _{i}\left\{\mu_{i j}^{k} \in \Im_{i}^{N W} \mid \mu_{i j}^{k} \leq \mu_{j}^{* k}\right\} \quad \forall j, k, \\
& \begin{array}{llll}
C_{1} & C_{2} & \ldots & C_{n}
\end{array} \\
& \wp^{-r}=E_{2}\left(\begin{array}{cccc}
\mu_{1}^{-r 1} & \mu_{2}^{-r 1} & \cdots & \mu_{n}^{-r 1} \\
\mu_{1}^{-r 2} & \mu_{2}^{-r 2} & \cdots & \mu_{n}^{-r 2} \\
\vdots & \vdots & \ddots & \vdots \\
\mu_{1}^{-r k} & \mu_{2}^{-r k} & \cdots & \mu_{n}^{-r k}
\end{array}\right)_{k \times n} \text {, } \\
& \mu_{j}^{-r k}=\max _{i}\left\{\mu_{i j}^{k} \in \Im_{i}^{N W} \mid \mu_{i j}^{k} \geq \mu_{j}^{* k}\right\} \quad \forall j, k .
\end{aligned}
$$

The hesitant fuzzy negative ideal solution is divided into hesitant fuzzy left and right negative ideal decision matrices to avoid risk at the decision level of decision-makers.

Meanwhile, the normalized hesitant fuzzy group decision matrix is constructed [37].

Step 8. Compute the separation measure from positive ideal decision matrix $\left(\pi_{i}^{* k}\right)$, left negative ideal decision matrix $\left(\pi_{i}^{-\ell k}\right)$, and right negative ideal decision matrix $\left(\pi_{i}^{-r k}\right)$ based on the following relations, respectively:

$$
\pi_{i}^{* k}=\sum_{j=1}^{n} \sqrt{\sum_{\lambda=1}^{l_{x_{i}}}\left(\left|\mu_{i j}^{\sigma(\lambda) k}\left(x_{i}\right)-\mu_{j}^{* \sigma(\lambda) k}\left(x_{i}\right)\right|^{2}\right)}
$$$$
\forall i, k,
$$

$$
\pi_{i}^{-\ell k}=\sum_{j=1}^{n} \sqrt{\sum_{\lambda=1}^{l_{x_{i}}}\left(\left|\mu_{i j}^{\sigma(\lambda) k}\left(x_{i}\right)-\mu_{j}^{-\ell \sigma(\lambda) k}\left(x_{i}\right)\right|^{2}\right)}
$$

$\forall i, k$,

$$
\pi_{i}^{-r k}=\sum_{j=1}^{n} \sqrt{\sum_{\lambda=1}^{l_{x_{i}}}\left(\left|\mu_{i j}^{\sigma(\lambda) k}\left(x_{i}\right)-\mu_{j}^{-r \sigma(\lambda) k}\left(x_{i}\right)\right|^{2}\right)}
$$

$\forall i, k$.
Step 9. Calculate the hesitant fuzzy relative closeness $\left(\psi_{i}\right)$ regarding separation measures as follows:

$$
\begin{aligned}
& \psi_{i}^{k}=\frac{\pi_{i}^{-\ell k}+\pi_{i}^{-r k}}{\pi_{i}^{-\ell k}+\pi_{i}^{* k}+\pi_{i}^{-r k}} \quad \forall i, k \\
& \psi_{i}=\frac{\prod_{k=1}^{K}\left(\pi_{i}^{-\ell k}\right)^{\frac{1}{K}}+\prod_{k=1}^{K}\left(\pi_{i}^{-r k}\right)^{\frac{1}{K}}}{\prod_{k=1}^{K}\left(\pi_{i}^{-\ell k}\right)^{\frac{1}{K}}+\prod_{k=1}^{K}\left(\pi_{i}^{* k}\right)^{\frac{1}{K}}+\prod_{k=1}^{K}\left(\pi_{i}^{-r k}\right)^{\frac{1}{K}}} \\
& \quad \forall i,
\end{aligned}
$$

where $\psi_{i}^{k}$ is the relative closeness of the $i$ th candidate regarding the $k$ th decision-maker.

Step 10. Rank the candidate Pareto optimal points by the descending sorting of the hesitant fuzzy relative closeness.

\section{Solution approach}

In this section, the proposed mixed integer non-linear programming model was converted to a linear model; then, the chance-constrained programming approach was provided to cope with the imprecise parameters. In addition, an efficient, simple augmented e-constraint (SAUGMECON) method was provided to convert the proposed method to a single objective function.

\subsection{Linearization}

As indicated in the proposed model (A.1), the first objective function and Constraints (6), (7), (10), (12)(14), and (17)-(19) were non-linear. In this respect, let $Z$ be an auxiliary variable, and $X$ a binary variable, and $Y$ a positive variable $(Z=X \times Y)$; then, the following constraints must be added to a non-linear model to obtain a linearized model:

$$
\begin{aligned}
& Z \geq Y-M(1-X), \\
& Z \leq Y+M(1-X), \\
& Z \leq M X, \\
& X \in \text { Binary, } \\
& Y, Z \in \text { Integer, }
\end{aligned}
$$

where $M$ is a positive large number. Hence, the linearization of the A.1 model was achieved by introducing some auxiliary variables and adding some constraints.

\subsection{Possibilistic chance-constraint programming approach}

In real cases, the lack of experimental data, the imprecise nature of parameters, and the characteristics 
of the system led to an uncertain situation. To address the issue, various ways of overcoming uncertainty exist. In this respect, probability theory and fuzzy set theory, regarding their problems, are of interest to scholars.

In this study, some imprecise parameters such as demand of each customer, the transportation time between the factories and the located distribution centers, and the transportation time between the located distribution centers and the customers were considered under fuzzy environment. In this respect, the actual demand of each product was specified daily and might alter during the planning horizon. In real cases, thus, specifying the precise value of customers' demand is impossible. In addition, determining the exact value of the transportation time between each facility is impossible and depends on some features such as weather condition, traffic volume, car crash, car breakdown, etc. Therefore, the aforementioned uncertain parameters should be determined based on experts' judgments and the historical data. To address the imprecise parameters, authors fitted a popular membership function into similar models. In this regard, a membership function, based on experts' judgments and the historical data, was found to be suitable for the considered uncertain parameters of the proposed bi-objective multi-echelon supply chain model with locating distribution centers.

To solve the proposed possibilistic bi-objective distribution center location model, a Possibilistic Chance-Constraint Programming (PCCP) approach based on [38-40] was tailored. To form the PCCP model, in this regard, an expected value operator (based on studies of [41-43]) was considered to model the objective function; in addition, the necessary measure to overcome the possibilistic chance constraints was provided. Hence, the second objective function and Constraints (6), (7), (10), (11), (19), (20), and (22) were used based on the necessary measure and linearization as follows:

\section{A.2:}

$$
\begin{gathered}
\min E\left[Z_{2}\right]=\sum_{t=1}^{T} \sum_{p=1}^{P} \sum_{i=1}^{N} \sum_{j=1}^{N} \eta_{i}^{C}\left(E\left[\tilde{d}_{i p}^{t}\right]-D_{j i p}^{t}\right) \\
+\sum_{t=1}^{T} \sum_{p=1}^{P} \sum_{f=1}^{F} \sum_{j=1}^{N} \eta_{j}^{H}\left(E_{j f p}^{t}-A_{f j p}^{t}\right), \\
\operatorname{Nec}\left\{\alpha_{j i p}^{t}=D X_{i j}^{t}+\tilde{\gamma}_{i j}^{t}+S_{i}^{p} D_{j i p}^{t}\right\} \geq \lambda_{1} \\
\forall i, j, p, t, \\
\operatorname{Nec}\left\{\beta_{f j p}^{t}=y_{f j} \tilde{\lambda}_{f j}^{t}+D Y_{f j}^{t}\right\} \geq \lambda_{2} \quad \forall j, f, p, t,
\end{gathered}
$$

$$
\begin{aligned}
& \operatorname{Nec}\left\{\sum_{i=1}^{N} \tilde{d}_{i p}^{t} \leq \sum_{j=1}^{N} \sum_{f=1}^{F} E_{j f p}^{t}\right\} \geq \hbar_{1} \quad \forall p, t \\
& \operatorname{Nec}\left\{\sum_{i=1}^{N} \kappa_{j i p}^{t}+b c_{j p}^{t-1}=\sum_{i=1}^{N} d_{i p}^{t}+I_{j p}^{t}\right\} \geq \lambda_{3} \\
& \forall j, p, t, \\
& \operatorname{Nec}\left\{\sum_{j=1}^{N} D_{j i p}^{t} \leq \tilde{d}_{i p}^{t}\right. \\
& \left.+\left(\sum_{t^{\prime}=1}^{T^{\prime}} \tilde{d}_{i p}^{t^{\prime}-1}-\sum_{t^{\prime}=1}^{T^{\prime}} \sum_{j=1}^{N} D_{j i p}^{t^{\prime}-1}\right)\right\} \geq \hbar_{2} \\
& \forall i, p, t \geq 2 \text {, } \\
& \operatorname{Nec}\left\{\sum_{j=1}^{N} D_{j i p}^{1} \leq \tilde{d}_{i p}^{1}\right\} \geq \hbar_{3} \quad \forall i, p, \\
& \operatorname{Nec}\left\{\sum_{i=1}^{N} \sum_{t=1}^{T} \kappa_{j i p}^{t}=\sum_{i=1}^{N} \sum_{t=1}^{T} d_{i p}^{t}\right\} \geq \lambda_{4} \quad \forall j, p, \\
& x_{i j}, y_{f j} \in\{0,1\} \quad \forall i, j, f \text {, } \\
& \vartheta_{j f p}^{t}, I_{j p}^{t}, b c_{j p}^{t}, \kappa_{j i p}^{t}, \alpha_{j i p}^{t}, \beta_{f j p}^{t}, A_{f j p}^{t}, D_{j i p}^{t}, E_{j f p}^{t}, \\
& D X_{i j}^{t}, D Y_{f j}^{t} \geq 0 \quad \forall i, j, f, p, t .
\end{aligned}
$$

In this respect, necessary measures for $t>k$ and $t<k$ to cope with possibilistic chance constraints are represented in Figures 3 and 4, respectively. To address the necessity of the aforementioned constraints (Eqs. (43)-(52)), the trapezoidal possibility distribution was adopted in which Eqs. (53) and (54) in Figure 3 and Eqs. (55) and (56) in Figure 4 should be considered.

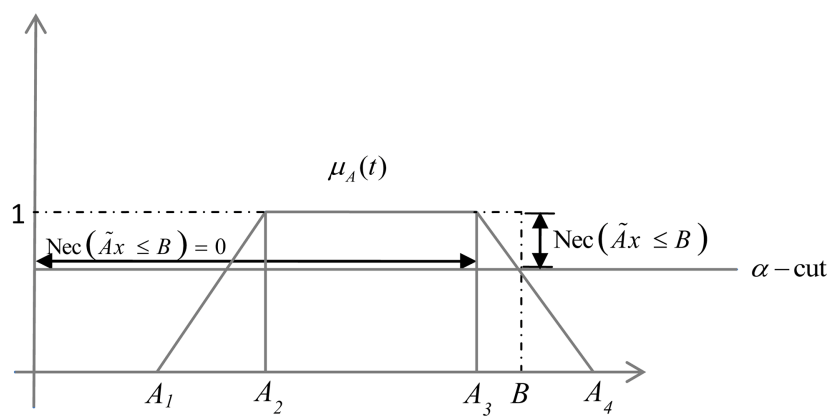

Figure 3. Necessity measure for $t>k$. 


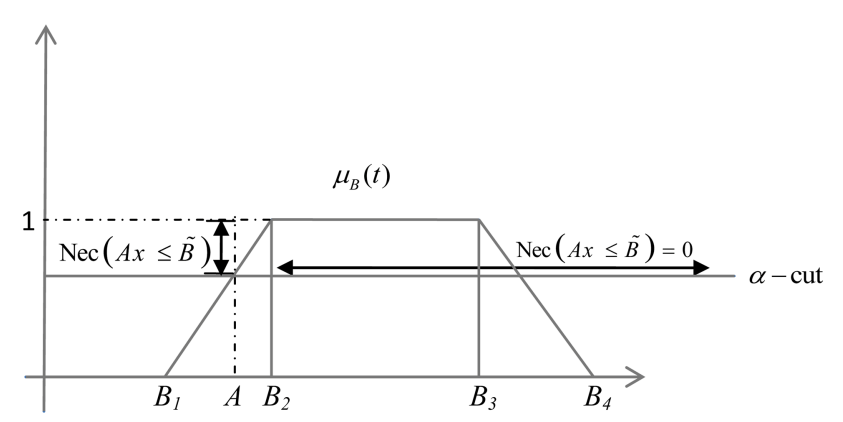

Figure 4. Necessity measure for $t<k$.

$$
\begin{aligned}
& \operatorname{Nec}(\tilde{A} x \leq B)=1-\sup _{t>k}\left(\mu_{A}(t)\right), \\
& \operatorname{Nec}(\tilde{A} x \leq B)= \begin{cases}0 & t<A_{3} \\
\frac{t-A_{3}}{A_{4}-A_{3}} & A_{3} \leq t<A_{4} \\
1 & t>A_{4}\end{cases} \\
& \operatorname{Nec}(A x \leq \tilde{B})=1-\sup _{t<k}\left(\mu_{B}(t)\right), \\
& \operatorname{Nec}(A x \leq \tilde{B})= \begin{cases}0 & t \geq B_{2} \\
\frac{B_{2}-t}{B_{2}-B_{1}} & B_{1} \leq t<B_{2} \\
1 & t<B_{1}\end{cases}
\end{aligned}
$$

Therefore, the equivalent crisp model, according to A.2 model, can be expressed as follows:

A.3:

$$
\begin{aligned}
\min E\left[Z_{2}\right] & =\sum_{t=1}^{T} \sum_{p=1}^{P} \sum_{i=1}^{N} \sum_{j=1}^{N} \eta_{i}^{C} \\
& \left(\frac{\left.d_{i p(1)}^{t}+d_{i p(2)}^{t}+d_{i p(3)}^{t}+d_{i p(4)}^{t}-D_{j i p}^{t}\right)}{4}\right. \\
& +\sum_{t=1}^{T} \sum_{p=1}^{P} \sum_{f=1}^{F} \sum_{j=1}^{N} \eta_{j}^{H}\left(E_{j f p}^{t}-A_{f j p}^{t}\right)
\end{aligned}
$$$$
\alpha_{j j p}^{t} \leq \frac{\lambda_{1}}{2} \gamma_{i j(3)}^{t}+\left(1-\frac{\lambda_{1}}{2}\right) \gamma_{i j(4)}^{t}+D X_{i j}^{t}+S_{i}^{p} D_{j i p}^{t}
$$$$
\forall i, j, p, t
$$$$
\alpha_{j j p}^{t} \geq \frac{\lambda_{1}}{2} \gamma_{i j(2)}^{t}+\left(1-\frac{\lambda_{1}}{2}\right) \gamma_{i j(1)}^{t}+D X_{i j}^{t}+S_{i}^{p} D_{j i p}^{t}
$$$$
\forall i, j, p, t
$$

$$
\beta_{f j p}^{t} \leq \frac{\lambda_{2}}{2} y_{f j} \lambda_{f j(3)}^{t}+\left(1-\frac{\lambda_{2}}{2}\right) y_{f j} \lambda_{f j(4)}^{t}+D Y_{f j}^{t}
$$$$
\forall j, f, p, t,
$$

$$
\begin{aligned}
& \beta_{f j p}^{t} \geq \frac{\lambda_{2}}{2} y_{f j} \lambda_{f j(2)}^{t}+\left(1-\frac{\lambda_{2}}{2}\right) y_{f j} \lambda_{f j(1)}^{t}+D Y_{f j}^{t} \\
& \forall j, f, p, t \\
& \hbar_{1} \sum_{i=1}^{N} d_{i p(4)}^{t}+\left(1-\hbar_{1}\right) \sum_{i=1}^{N} d_{i p(3)}^{t} \leq \sum_{j=1}^{N} \sum_{f=1}^{F} E_{j f p}^{t} \\
& \quad \forall p, t
\end{aligned}
$$

$$
\begin{aligned}
\sum_{i=1}^{N} \kappa_{j i p}^{t} & +b c_{j p}^{t-1} \leq \frac{\lambda_{3}}{2} \sum_{i=1}^{N} d_{i p(3)}^{t} \\
& +\left(1-\frac{\lambda_{3}}{2}\right) \sum_{i=1}^{N} d_{i p(4)}^{t}+I_{j p}^{t} \quad \forall j, p, t,
\end{aligned}
$$

$$
\begin{aligned}
\sum_{i=1}^{N} \kappa_{j i p}^{t} & +b c_{j p}^{t-1} \geq \frac{\lambda_{3}}{2} \sum_{i=1}^{N} d_{i p(2)}^{t} \\
& +\left(1-\frac{\lambda_{3}}{2}\right) \sum_{i=1}^{N} d_{i p(1)}^{t}+I_{j p}^{t} \quad \forall j, p, t,
\end{aligned}
$$

$\sum_{j=1}^{N} D_{j i p}^{t} \leq \hbar_{2} d_{i p(1)}^{t}+\left(1-\hbar_{2}\right) d_{i p(2)}^{t}+\left(\hbar_{2} \sum_{t^{\prime}=1}^{T^{\prime}} d_{i p(1)}^{t^{\prime}-1}\right.$

$$
\left.+\left(1-\hbar_{2}\right) \sum_{t^{\prime}=1}^{T^{\prime}} d_{i p(2)}^{t^{\prime}-1}-\sum_{t^{\prime}=1}^{T^{\prime}} \sum_{j=1}^{N} D_{j i p}^{t^{\prime}-1}\right)
$$

$\forall i, p, t \geq 2$,

$\sum_{j=1}^{N} D_{j i p}^{1} \leq \hbar_{3} d_{i p(1)}^{1}+\left(1-\hbar_{3}\right) d_{i p(2)}^{1} \quad \forall i, p$,

$$
\begin{aligned}
\sum_{i=1}^{N} \sum_{t=1}^{T} \kappa_{j i p}^{t} & \leq \frac{\lambda_{4}}{2} \sum_{i=1}^{N} \sum_{t=1}^{T} d_{i p(3)}^{t} \\
+\left(1-\frac{\lambda_{4}}{2}\right) \sum_{i=1}^{N} \sum_{t=1}^{T} d_{i p(4)}^{t} & \forall j, p,
\end{aligned}
$$

$$
\begin{aligned}
\sum_{i=1}^{N} \sum_{t=1}^{T} \kappa_{j i p}^{t} \geq \frac{\lambda_{4}}{2} \sum_{i=1}^{N} \sum_{t=1}^{T} d_{i p(2)}^{t} & \\
+\left(1-\frac{\lambda_{4}}{2}\right) \sum_{i=1}^{N} \sum_{t=1}^{T} d_{i p(1)}^{t} & \forall j, p, \\
x_{i j}, y_{f j} \in\{0,1\} & \forall i, j, f,
\end{aligned}
$$




$$
\begin{array}{rr}
\vartheta_{j f p}^{t}, I_{j p}^{t}, b c_{j p}^{t}, \kappa_{j i p}^{t}, \alpha_{j i p}^{t}, \beta_{f j p}^{t}, A_{f j p}^{t}, D_{j i p}^{t}, E_{j f p}^{t}, \\
D X_{i j}^{t}, D Y_{f j}^{t} \geq 0 & \forall i, j, f, p, t .
\end{array}
$$

In the aforementioned formulation, it is supposed that the possibilistic chance constraints should be satisfied with a confidence level greater than 0.5 (i.e., $\lambda_{1}, \lambda_{2}, \lambda_{3}$, $\left.\lambda_{4}, \hbar_{1}, \hbar_{2}, \hbar_{3}>0.5\right)$. In this regard, experts should specify the minimum confidence level of possibilistic chance constraints. Usually, experts specify some initial values for each confidence level and, then, based on an interactive experiment, the confidence level that satisfies the experts' criteria better than the others is considered as the final value.

\subsection{Multi-objective approach}

The proposed bi-objectives model was converted to the single-objective model based on an efficient simple augmented e-constraint (SAUGMECON) method, which was presented by Zhang and Reimann [44], as follows:

$$
\begin{array}{ll}
\min & \left(f_{1}(x)+\delta\left(\frac{f_{2}(x)}{r_{2}}+\frac{f_{3}(x)}{r_{3}}+\cdots+\frac{f_{p}(x)}{r_{p}}\right)\right) \\
\text { s.t. } & f_{2}(x) \leq \varepsilon_{2} \\
& f_{3}(x) \leq \varepsilon_{3} \\
& \vdots \\
& f_{p}(x) \leq \varepsilon_{p} \\
& x \in S
\end{array}
$$

where $r_{i}, i \in[1, p-1]$ is the range of the $i$ th objective, and $\delta$ is a small number (usually between $10^{-3}$ and $\left.10^{-6}\right)$. It has been proven that the AUGMECON method only generates efficient solutions [45]. Hence, the SAUGMECON method was established by considering both features of traditional e-constraint and the AUGMECON methods. In this regard, the traditional e-constraint was considered to add some inequalities to the objectives in the constrained space. Then, the sum of weighted constraint objectives was combined with an objective function.

\section{Case study}

In this section, a real case study of a producer company of dairy products is provided to evaluate the efficiency and applicability of the proposed bi-objective distribution center location model. In doing so, the performance of the presented bi-objective distribution center location model is shown during a 7-day period. In the following, an outline of the case study and the obtained results is discussed.

\subsection{Outline of the case study}

Kalleh dairy company was established in 1991 and 1992 in Amol, Mazandaran, Iran. Kalleh dairy Co. followed the strategy of increasing customer satisfaction through the diversity of products and their high quality. This company has become one of the most successful and largest companies in the field of dairy products in the Middle East. Based on the company's documents, there were various activities in the company's supply process that were clearly meant, as we realized, to determine the best location of the depot with respect to warehouse considerations. The cold chain distribution system was launched to enhance the supply chain, in which the perishable delivery system was optimized. Thus, the necessity of determining a suitable location of the depots regarding warehouse optimization gains greater significance. Kalleh dairy Co. developed their producers in Iran, and the locations of the three main factories are shown in Figure 5. These factories produced different dairy products, and the demand of the located warehouses was satisfied based on the productions of the three factories. Moreover, the aforementioned strategy of the Kalleh dairy Co. in the eastern Mazandaran was applied in one warehouse. Therefore, the warehouse location based on the above statements encourages a single distribution center location.

Hence, there are 26 customers in the eastern part of Mazandaran whose demands should be satisfied. In this regard, the customers' demand should be served based on their importance level (amount of monthly purchase, size of the store, etc.). Accordingly, Figure 6 represents the location of considered customers. With respect to different perishable products, the customers' demand was applied in the warehouse, and the warehouse order was applied in the factories. Due to the dispersion of the customers and factories, it is interesting to determine an appropriate located distribution center. To address this issue, an important factor in minimizing the amount of backorder for important customers and candidate customers regarding the distribution center location was determined. Moreover, the relative importance of each customer was specified based on the amount of purchases and distance from the depot. However, a daily report was sent by the corresponding warehouse supervisor and sales manager to solve the distribution center location problem.

\subsection{Results}

\subsubsection{Results of the proposed distribution center location model}

In order to solve the distribution center location problem based on the main bi-objectives, i.e., minimizing the total cost and the amount of backorder for important customers/located distribution centers, the proposed model is to be assessed. Accordingly, 26 cus- 


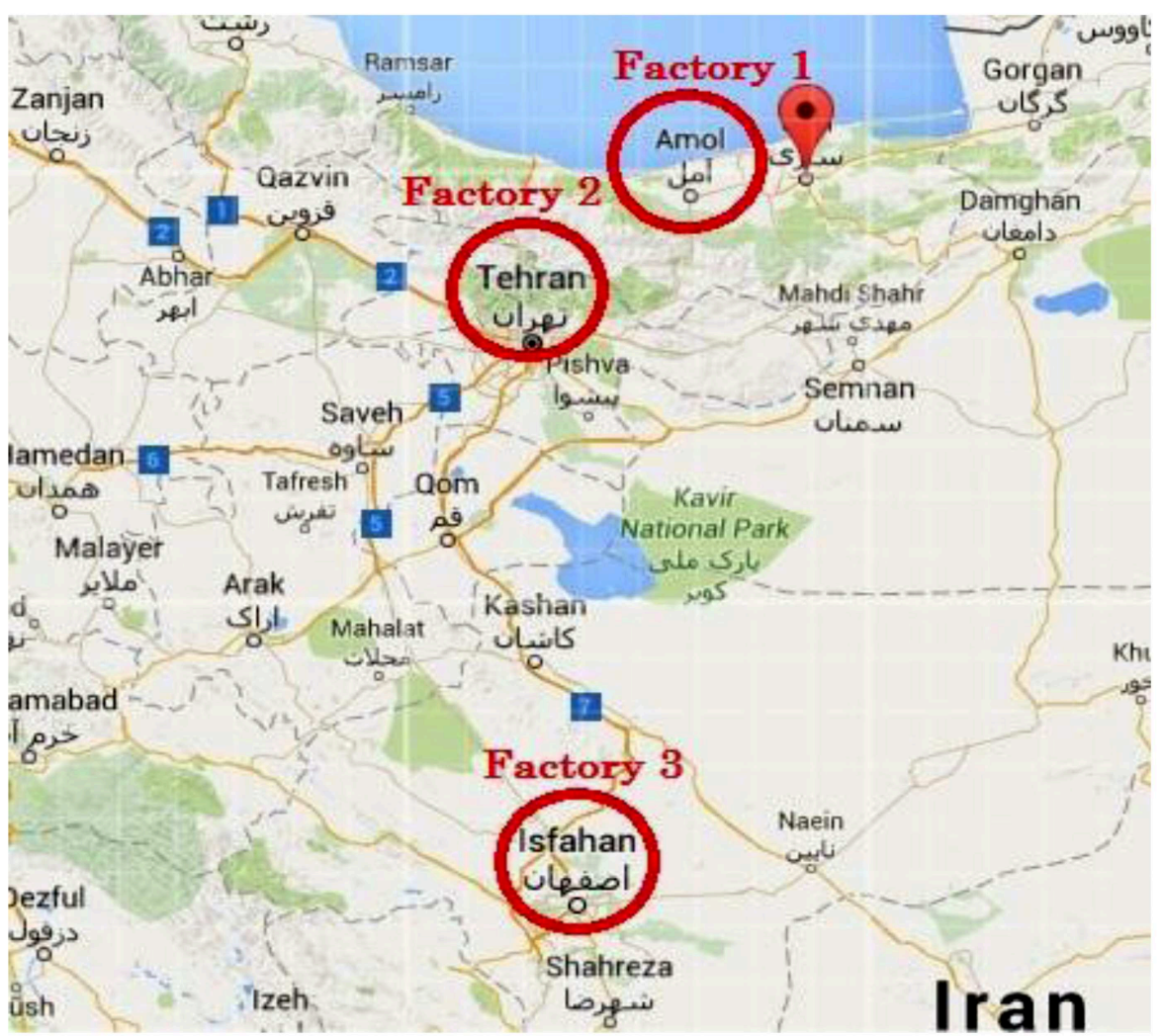

Figure 5. The location of each factory.

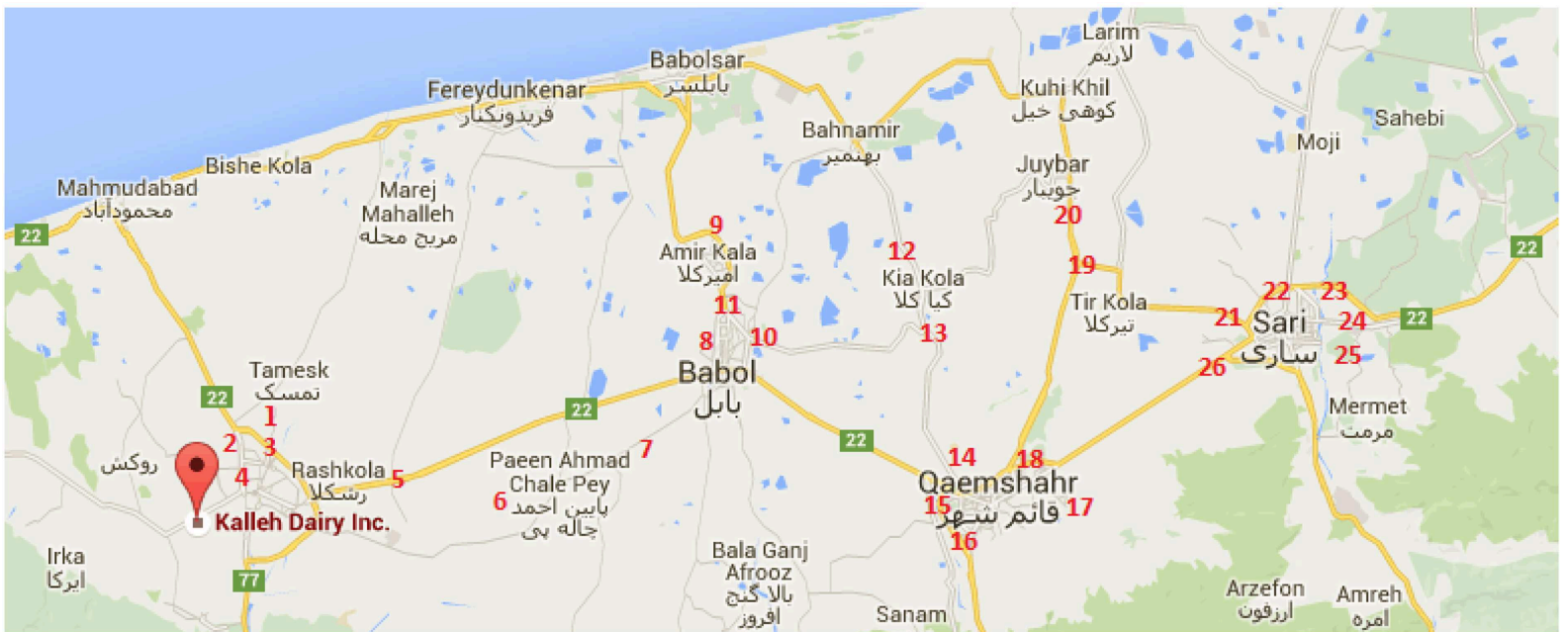

Figure 6. The location of each customer.

tomers from various areas and sales lines were chosen to facilitate the procedure of solving the defined case study. The main factor concerns the determination of the most suitable distribution center regarding both objectives. Due to the nature of dairy products, the ordering procedure of perishable dairy products was specified day by day and could not be determined precisely. Thus, the fuzzy information could help us solve the problem appropriately. The data were collected based on the existing situation of the Kalleh company in Sari branch and the performance of the factories during 7 working days $(t=7)$.

In this respect, relative importance of the 26 customers and the demand of products were considered in relation to the major products as yogurt, buttermilk, milk, cheese, and sauce. Hence, the relative significance of each customer was determined by experts/decisionmakers based on RFM model (regency, frequency, and monetary) during 7 days. The transportation routes were determined in order to deliver the products to the 
Table 3. The obtained Pareto optimal points by SAUGMECON method.

\begin{tabular}{ccc}
$\begin{array}{c}\text { Pareto optimal } \\
\text { points }\end{array}$ & $\begin{array}{c}\text { First objective } \\
\text { value }\end{array}$ & $\begin{array}{c}\text { Second objective } \\
\text { value }\end{array}$ \\
\hline 1 & 1509 & 209.38 \\
2 & 1533 & 194.98 \\
3 & 1568 & 184.06 \\
4 & 1601 & 174.57 \\
5 & 1649 & 165.63 \\
6 & 1698 & 157.47 \\
7 & 1753 & 151.19 \\
8 & 1813 & 146.03 \\
9 & 1887 & 142.25 \\
10 & 1926 & 139.44 \\
\hline
\end{tabular}

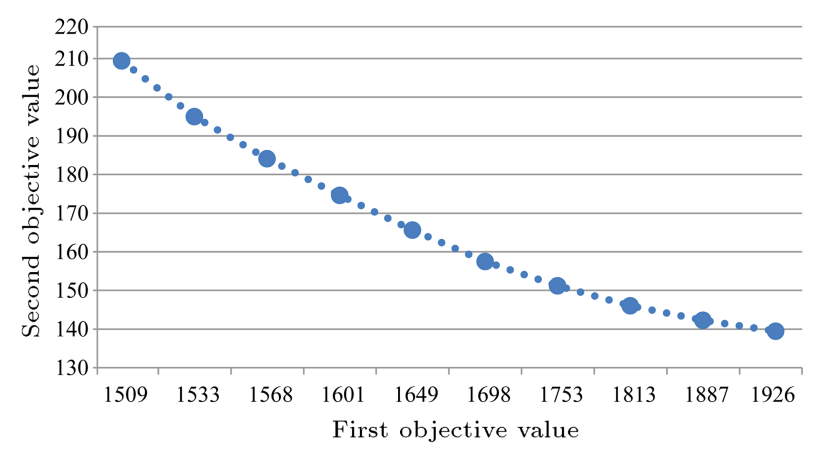

Figure 7. The conflict of both objective functions.

26 selected customers. Subsequently, a certain time window was specified for each selected customer and candidate distribution center for the location.

However, to determine the value of objective functions, the SAUGMECON method was considered to achieve a single mathematical model. In this regard, Table 3 represents the obtained Pareto optimal points. In addition, Figure 7 shows the conflict between the considered objective functions. The results show that the location of the important customers is far from the located distribution centers. Therefore, the reduction of the backorder of important customers led to an increase in the total cost in the first objective function. It should be noted that the proposed model was solved by ILOG CPLEX 10.1 optimization software, and the results were obtained by a computer equipped with $3 \mathrm{GHz}$ processor and $4 \mathrm{~GB}$ RAM.

\subsubsection{Results of the proposed evaluation and ranking method}

In addition, to choose the most suitable Pareto optimal point, the proposed novel ranking and evaluation method was considered. In this regard, two decisionmakers $\left(E_{1}, E_{2}\right)$ evaluated the obtained ten Pareto optimal points $\left(p_{1}, p_{2}, \cdots, p_{10}\right)$ based on the three criteria $\left(C_{1}, C_{2}, C_{3}\right)$. The risk preferences of the first and
Table 4. The rating of Pareto optimal points based on preferences and judgments of experts.

\begin{tabular}{|c|c|c|c|c|}
\hline \multirow{2}{*}{ Experts } & \multirow{2}{*}{$\begin{array}{c}\text { Pareto } \\
\text { optimal points }\end{array}$} & \multicolumn{3}{|c|}{ Criteria } \\
\hline & & $C_{1}$ & $C_{2}$ & $C_{3}$ \\
\hline \multirow{10}{*}{$E_{1}$} & $p_{1}$ & VVP & EG & VVP \\
\hline & $p_{2}$ & VVP & VG & VP \\
\hline & $p_{3}$ & VP & G & VP \\
\hline & $p_{4}$ & $\mathrm{MP}$ & G & $\mathrm{P}$ \\
\hline & $p_{5}$ & $\mathrm{MG}$ & MG & $\mathrm{P}$ \\
\hline & $p_{6}$ & MG & $\mathrm{M}$ & MP \\
\hline & $p_{7}$ & MG & $\mathrm{P}$ & $\mathrm{M}$ \\
\hline & $p_{8}$ & G & $\mathrm{P}$ & G \\
\hline & $p_{9}$ & $\mathrm{G}$ & VP & G \\
\hline & $p_{10}$ & VVG & VP & VVG \\
\hline \multirow{10}{*}{$E_{2}$} & $p_{1}$ & VVP & $\mathrm{EG}$ & VVP \\
\hline & $p_{2}$ & VP & VVG & $\mathrm{VP}$ \\
\hline & $p_{3}$ & VP & VG & $\mathrm{P}$ \\
\hline & $p_{4}$ & $\mathrm{P}$ & MG & MP \\
\hline & $p_{5}$ & M & $\mathrm{M}$ & MP \\
\hline & $p_{6}$ & M & MP & $\mathrm{M}$ \\
\hline & $p_{7}$ & MG & MP & M \\
\hline & $p_{8}$ & G & $\mathrm{P}$ & G \\
\hline & $p_{9}$ & VG & VP & VG \\
\hline & $p_{10}$ & VVG & VVP & EG \\
\hline
\end{tabular}

Table 5. The relative importance of each criterion based on experts' opinions.

\begin{tabular}{cccc}
\hline \multirow{2}{*}{ Experts } & \multicolumn{3}{c}{ Criteria } \\
\cline { 2 - 4 } & $\boldsymbol{C}_{\mathbf{1}}$ & $\boldsymbol{C}_{\boldsymbol{2}}$ & $\boldsymbol{C}_{\boldsymbol{3}}$ \\
\hline$E_{1}$ & $\mathrm{H}$ & $\mathrm{VH}$ & $\mathrm{M}$ \\
$E_{2}$ & $\mathrm{VH}$ & $\mathrm{VH}$ & $\mathrm{H}$ \\
\hline
\end{tabular}

second decision-makers were pessimistic and moderate, respectively. Meanwhile, the group decision-making matrix for rating the Pareto optimal points and the relative importance of each criterion are represented in Tables 4 and 5, respectively. In addition, the considered criteria are defined as follows:

- Customers satisfaction $\left(C_{1}\right)$;

- Financial performance $\left(C_{2}\right)$;

- Backorder quantity $\left(C_{3}\right)$.

The hesitant fuzzy group decision matrix was normalized based on Eq. (26). Then, the weighted, normalized hesitant fuzzy group decision matrix for each candidate regarding the criteria weights was determined by using Eq. (28). Based on Eqs. (30)(32), the hesitant fuzzy positive ideal decision matrix 
Table 6. The separation measures for each Pareto optimal points.

\begin{tabular}{|c|c|c|c|c|c|c|}
\hline \multirow{2}{*}{$p_{i}$} & \multicolumn{2}{|c|}{$\pi_{i}^{* k}$} & \multicolumn{2}{|c|}{$\pi_{i}^{-\ell k}$} & \multicolumn{2}{|c|}{$\pi_{i}^{-r k}$} \\
\hline & $E_{1}$ & $E_{2}$ & $E_{1}$ & $E_{2}$ & $E_{1}$ & $E_{2}$ \\
\hline$p_{1}$ & 0.94887 & 0.09860 & 0.80991 & 0.95754 & 1.51893 & 0.47148 \\
\hline$p_{2}$ & 1.00155 & 0.14320 & 0.80991 & 0.96484 & 1.37005 & 0.34980 \\
\hline$p_{3}$ & 0.76896 & 0.38583 & 0.63000 & 0.79479 & 1.33902 & 0.30872 \\
\hline$p_{4}$ & 0.80333 & 0.22536 & 0.82831 & 1.04699 & 1.17183 & 0.26765 \\
\hline$p_{5}$ & 0.67896 & 0.59249 & 0.54000 & 1.00145 & 1.24902 & 0.35107 \\
\hline$p_{6}$ & 0.66496 & 0.54451 & 0.87668 & 1.14115 & 1.03346 & 0.42249 \\
\hline$p_{7}$ & 0.33911 & 0.72749 & 0.87985 & 0.86645 & 0.90917 & 0.48607 \\
\hline$p_{8}$ & 0.28391 & 0.82392 & 0.89773 & 1.15056 & 0.65241 & 0.53758 \\
\hline$p_{9}$ & 0.28197 & 1.01630 & 0.95417 & 1.15526 & 0.65485 & 0.44625 \\
\hline$p_{10}$ & 0.08710 & 1.02581 & 0.99259 & 1.21745 & 0.37755 & 0.65731 \\
\hline
\end{tabular}

Table 7. The hesitant fuzzy relative closeness of each Pareto optimal point and their ranking.

\begin{tabular}{ccc}
\hline $\begin{array}{c}\text { Pareto } \\
\text { optimal points }\end{array}$ & $\boldsymbol{\psi}_{\boldsymbol{i}}$ & $\begin{array}{c}\text { Ranking the } \\
\text { Pareto optimal points }\end{array}$ \\
\hline$p_{1}$ & 0.69794 & $p_{6}$ \\
$p_{2}$ & 0.71533 & $p_{5}$ \\
$p_{3}$ & 0.73081 & $p_{4}$ \\
$p_{4}$ & 0.84243 & $p_{7}$ \\
$p_{5}$ & 0.90368 & $p_{3}$ \\
$p_{6}$ & 0.92004 & $p_{8}$ \\
$p_{7}$ & 0.80270 & $p_{2}$ \\
$p_{8}$ & 0.71911 & $p_{1}$ \\
$p_{9}$ & 0.66101 & $p_{9}$ \\
$p_{10}$ & 0.62852 & $p_{10}$ \\
\hline
\end{tabular}

and the hesitant fuzzy right/left negative ideal decision matrices were provided, respectively. Then, the separation measures were computed by utilizing Eqs. (33)(35). The results are given in Table 6. Finally, the candidates were ranked in descending order of hesitant fuzzy relative closeness for each alternative with respect to Eq. (37), as presented in Table 7.

\section{Discussion}

In this section, the obtained results of the proposed model are compared to actual practice to clarify the merits and advantages of the proposed approach. In this case, the obtained Pareto optimal points of the objective functions have been approved by experts. In this respect, considering the worst Pareto optimal point of the first and second objective functions shows that the proposed approach can improve the total costs by $17.3 \%$ and, also, the customer satisfaction by minimizing the deviation of delivered products for important customers and candidate customers by $11.7 \%$. Four

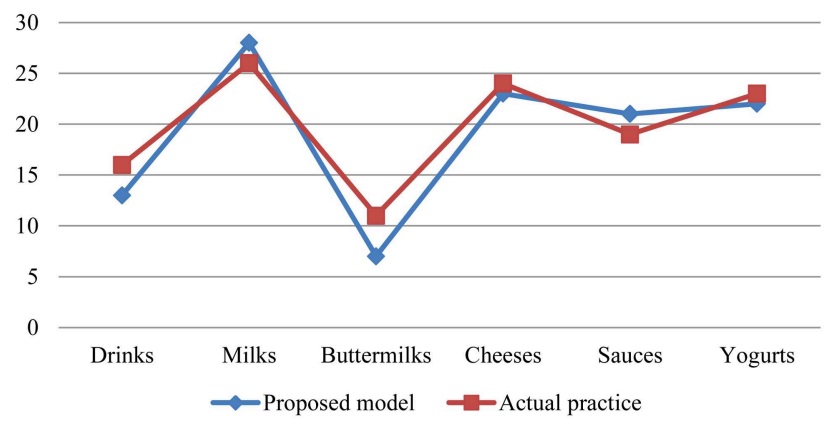

Figure 8. Comparison between the results of the proposed model and actual practice for a quantity of perished products in the planning horizon.

comparison indicators including the quantity of the perished products, the backorder level of the located distribution center, the backorder level of the factories, and the inventory level of the located distribution center are considered, which will be discussed in the following sections.

\subsection{The quantity of the perished products}

In this section, based on the quantity of the perished products during transportation of the perishable products from the factory to the located distribution centers and the quantity of the perished products at the depots, the determined quantity of the perished products in the planning horizon were considered so as to compare the results obtained by the proposed approach with the current practice. The results show that the proposed bi-objective multi-echelon supply chain model for perishable products reduces the perished products by $4.2 \%$. Figure 8 shows the comparison results between the quantity of the perished products in the planning horizon of the proposed and the actual models.

\subsection{The backorder level of the located distribution center}

When the orders of the customers from the located 


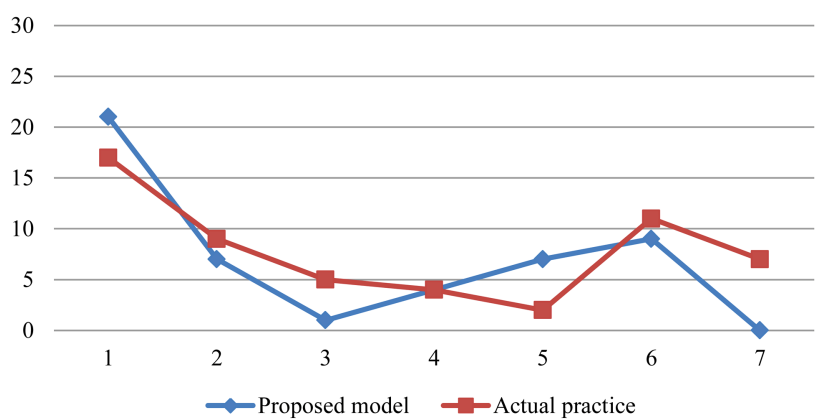

Figure 9. Comparison between the results of the proposed model and actual practice for the backorder level of located distribution center in each period.

distribution center are not fulfilled in the current period, it should be satisfied at the end of the planning horizon. Of note, the backorder level of the located distribution centers is related to the quantity of the perished products at the located distribution center and during the transportation of products from the factories to the located distribution center. Therefore, the backorder level management is an important factor for companies to increase the customers' satisfaction and decrease their costs. Hence, Figure 9 represents the backorder level results of the proposed model versus the actual practice in seven days. In addition, the obtained results of the comparison of backorder levels indicate that the proposed model could improve the backorder level management by $10.9 \%$.

\subsection{The backorder level of the factories}

The backorder level of the factories as well as that of the located distribution centers, when orders of the located distribution centers from the factories are not shipped in the current period, should be satisfied at the end of the planning horizon. Hence, the results show that the proposed distribution center location model can improve the backorder level of the factories by $12.16 \%$ versus the current practice. In this respect, Figure 10 shows the comparison results of the proposed model versus the actual practice at the backorder level of the factories' indicators in seven days.

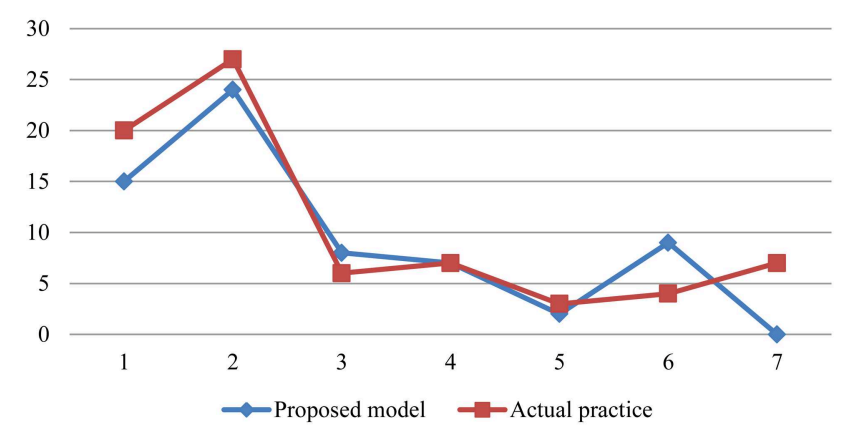

Figure 10. Comparison between the results of proposed model and actual practice for the backorder level of factories in each period.

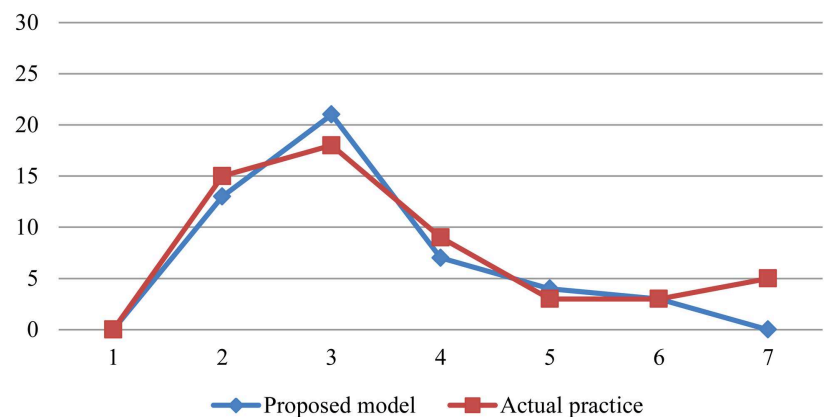

Figure 11. Comparison between the results of the proposed model and actual practice for the inventory level of the located distribution center in each period.

\subsection{The inventory level of the located distribution center}

The inventory level of the located distribution center is highly associated with the increasing holding cost. Therefore, this indicator as a main factor should be managed to minimize the holding cost and the backorder level. However, the comparison between the obtained results of the proposed model and actual practice showed that the proposed distribution center location model could improve the inventory level of the located distribution center by $9.4 \%$. Figure 11 shows the comparison between the proposed model and the actual practice for the inventory level of the located distribution center in seven days.

\section{Conclusions and future directions}

In this paper, a novel bi-objective distribution center location model was proposed for perishable products to optimize the location of the distribution center and the distribution system of the considered dairy producer company. Then, a new evaluation approach was presented based on the group decision analysis and the last aggregation approach under hesitant fuzzy set environment to evaluate and rank the obtained Pareto optimal points from the proposed multi-objective model. In this respect, the last aggregation could prevent the data loss, and considering the hesitant fuzzy information could decrease the margin of errors. Moreover, the possibilistic chance-constrained programming approach was applied to address the existing uncertainty in the presented bi-objective mathematical model. A real case study was provided to show the feasibility and efficiency of the proposed approach. Hence, 3 factories and 26 customers in eastern Mazandaran were considered, and the transportation routes were supposed known. Accordingly, based on the proposed model, 10 Pareto optimal points were obtained regarding the SAUGMECON approach. Then, the proposed hesitant fuzzy evaluation approach was implemented to rank the achieved Pareto optimal points. Finally, the obtained results of the proposed model versus the 
current practice were discussed based on both objective functions and four indicators as the quantity of the perished products, the backorder level of the located distribution center, the backorder level of the factories, and the inventory level of the located distribution center. Thereby, the comparative analysis showed that the proposed model could enhance the current system of the company in all considered indicators that improved the perished products by $4.2 \%$, the backorder level management by $10.9 \%$, the backorder level of the factories by $12.16 \%$, and the inventory level of the located distribution center by $9.4 \%$. Furthermore, considering the worst Pareto optimal point of the first and second objective functions indicated that the proposed approach could reduce the total costs by $17.3 \%$ and, also, improve the customer satisfaction by minimizing the deviation of delivered products for important customers and candidate customers by $11.7 \%$. For future directions, obtaining the optimal transportation routes from the located distribution center to the customers could enhance the proposed model. In addition, the application of a heuristic/metaheuristic solution approach could solve the problem on large scales.

\section{References}

1. Ebrahimnejad, S., Mousavi, S.M., and H. Seyrafianpour "Risk identification and assessment for buildoperate-transfer projects: A fuzzy multi attribute decision making model", Expert Systems with Applications, 37(1), pp. 575-586 (2010).

2. Vahdani, B., Mousavi, S.M., Hashemi, H., Mousakhani, M., and Tavakkoli-Moghaddam, R. "A new compromise solution method for fuzzy group decision-making problems with an application to the contractor selection", Engineering Applications of Artificial Intelligence, 26(2), pp. 779-788 (2013).

3. Ze-shui, X. "A multi-attribute group decision making method based on term indices in linguistic evaluation scales [J]", Journal of Systems Engineering, 1, p. 13 (2005).

4. Makui, A., Mojtahedi, S.M., and Mousavi, S.M. "Project risk identification and analysis based on group decision making methodology in a fuzzy environment", International Journal of Management Science and Engineering Management, 5(2), pp. 108-118 (2010).

5. Zadeh, L.A. "Fuzzy sets", Information and Control, 8(3), pp. 338-353 (1965).

6. Dubois, D.J., Fuzzy Sets and Systems: Theory and Applications, 144, Academic Press (1980).

7. Miyamoto, S., Multisets and Fuzzy Multisets, in Soft Computing and Human-Centered Machines, Springer, pp. 9-33 (2000).
8. Turksen, I.B. "Interval valued fuzzy sets based on normal forms", Fuzzy Sets and Systems, 20(2), pp. 191-210 (1986).

9. Zadeh, L.A. "The concept of a linguistic variable and its application to approximate reasoning-I", Information Sciences, 8(3), pp. 199-249 (1975).

10. Atanassov, K.T. "Intuitionistic fuzzy sets", Fuzzy sets and Systems, 20(1), pp. 87-96 (1986).

11. Torra, V. and Narukawa, Y. "On hesitant fuzzy sets and decision", In Fuzzy Systems", FUZZ-IEEE 2009. IEEE International Conference on, IEEE (2009).

12. Torra, V. "Hesitant fuzzy sets", International Journal of Intelligent Systems, 25(6), pp. 529-539 (2010).

13. Zhang, N. and Wei, G. "Extension of VIKOR method for decision making problem based on hesitant fuzzy set", Applied Mathematical Modelling, 37(7), pp. 49384947 (2013).

14. $\mathrm{Xu}, \mathrm{Z}$. and Zhang, $\mathrm{X}$. "Hesitant fuzzy multi-attribute decision making based on TOPSIS with incomplete weight information", Knowledge-Based Systems, 52, pp. 53-64 (2013).

15. Wei, G. and Zhang, N. "A multiple criteria hesitant fuzzy decision making with Shapley value-based VIKOR method", Journal of Intelligent \& Fuzzy Systems: Applications in Engineering and Technology, 26(2), pp. 1065-1075 (2014).

16. Chen, N. and Xu, Z. "Hesitant fuzzy ELECTRE II approach: A new way to handle multi-criteria decision making problems", Information Sciences, 292, pp. 175-197 (2015).

17. Joshi, D. and Kumar, S. "Interval-valued intuitionistic hesitant fuzzy Choquet integral based TOPSIS method for multi-criteria group decision making", European Journal of Operational Research, 248(1), pp. 183-191 (2016).

18. Qin, J., Liu, X., and Pedrycz, W. "An extended TODIM multi-criteria group decision making method for green supplier selection in interval type-2 fuzzy environment", European Journal of Operational Research, 258(2), pp. 626-638 (2017).

19. Ghodratnama, A., Tavakkoli-Moghaddam, R., and Azaron, A. "A fuzzy possibilistic bi-objective hub covering problem considering production facilities, time horizons and transporter vehicles", The International Journal of Advanced Manufacturing Technology, 66(14), pp. 187-206 (2013).

20. Mohammadi, M., Jolai, F., and TavakkoliMoghaddam, R. "Solving a new stochastic multi-mode p-hub covering location problem considering risk by a novel multi-objective algorithm", Applied Mathematical Modelling, 37(24), pp. 10053-10073 (2013). 
21. Rahimi, M., Baboli, A., and Rekik, Y. "A bi-objective inventory routing problem by considering customer satisfaction level in context of perishable product", In Computational Intelligence in Production and Logistics Systems (CIPLS), 2014 IEEE Symposium on, IEEE (2014).

22. Ebrahimi Zade, A., Sadegheih, A., and Lotfi, M.M. "A modified NSGA-II solution for a new multi-objective hub maximal covering problem under uncertain shipments", Journal of Industrial Engineering International, 10(4), pp. 185-197 (2014).

23. Pasandideh, S.H.R., Niaki, S.T.A., and Asadi, K. "Biobjective optimization of a multi-product multi-period three-echelon supply chain problem under uncertain environments: NSGA-II and NRGA", Information Sciences, 292, pp. 57-74 (2015).

24. Pasandideh, S.H.R., Niaki, S.T.A., and Asadi, K. "Optimizing a bi-objective multi-product multi-period three echelon supply chain network with warehouse reliability", Expert Systems with Applications, 42(5), pp. 2615-2623 (2015).

25. Khalili-Damghani, K., Abtahi, A.-R., and Ghasemi, A. "A new bi-objective location-routing problem for distribution of perishable products: Evolutionary computation approach", Journal of Mathematical Modelling and Algorithms in Operations Research, 14(3), pp. 287-312 (2015).

26. Sarrafha, K., Rahmati, S.H.A., Niaki, S.T.A., and Zaretalab, A. "A bi-objective integrated procurement, production, and distribution problem of a multiechelon supply chain network design: A new tuned MOEA", Computers \& Operations Research, 54, pp. 35-51 (2015).

27. Alavidoost, M., Tarimoradi, M., and Zarandi, M.F. "Bi-objective mixed-integer nonlinear programming for multi-commodity tri-echelon supply chain networks", Journal of Intelligent Manufacturing, 29(4), pp. 1-18 (2015).

28. Ghodratnama, A., Tavakkoli-Moghaddam, R., and Azaron, A. "Robust and fuzzy goal programming optimization approaches for a novel multi-objective hub location-allocation problem: A supply chain overview", Applied Soft Computing, 37, pp. 255-276 (2015).

29. Pasandideh, S.H.R., Niaki, S.T.A., and Sheikhi, M. "A bi-objective hub maximal covering location problem considering time-dependent reliability and the second type of coverage", International Journal of Management Science and Engineering Management, 11(4), pp. 1-8 (2015).

30. Maghsoudlou, H., Kahag, M.R., Niaki, S.T.A., and Pourvaziri, H. "Bi-objective optimization of a threeechelon multi-server supply-chain problem in congested systems: Modeling and solution", Computers \& Industrial Engineering, 99, pp. 41-62 (2016).
31. Ghezavati, V. and Beigi, M. "Solving a bi-objective mathematical model for location-routing problem with time windows in multi-echelon reverse logistics using metaheuristic procedure", Journal of Industrial Engineering International, 12(4), pp. 469-483 (2016).

32. Ebrahimi, S.B. "A bi-objective model for a multiechelon supply chain design considering efficiency and customer satisfaction: a case study in plastic parts industry", The International Journal of Advanced Manufacturing Technology, 95(9-12), pp. 1-19 (2017).

33. Habibi-Kouchaksaraei, M., Paydar, M.M., and AsadiGangraj, E. "Designing a bi-objective multi-echelon robust blood supply chain in a disaster", Applied Mathematical Modelling, 55, pp. 583-599 (2018).

34. Farahani, P., Grunow, M., and Günther, H.O. "Integrated production and distribution planning for perishable food products", Flexible Services and Manufacturing Journal, 24(1), pp. 28-51 (2012).

35. Xia, M. and $\mathrm{Xu}, \mathrm{Z}$. "Hesitant fuzzy information aggregation in decision making", International Journal of Approximate Reasoning, 52(3), pp. 395-407 (2011).

36. Yue, Z. "An extended TOPSIS for determining weights of decision makers with interval numbers", KnowledgeBased Systems, 24(1), pp. 146-153 (2011).

37. Zhu, B., Xu, Z., and Xia, M. "Hesitant fuzzy geometric Bonferroni means", Information Sciences, 205, pp. 7285 (2012).

38. Liu, B. and Iwamura, K. "Chance constrained programming with fuzzy parameters", Fuzzy Sets and Systems, 94(2), pp. 227-237 (1998).

39. Inuiguchi, M., Ichihashi, H., and Kume, Y. "Modality constrained programming problems: a unified approach to fuzzy mathematical programming problems in the setting of possibility theory", Information Sciences, 67(1), pp. 93-126 (1993).

40. Pishvaee, M., Razmi, J., and Torabi, S.A. "Robust possibilistic programming for socially responsible supply chain network design: A new approach", Fuzzy Sets and Systems, 206, pp. 1-20 (2012).

41. Dubois, D. and Prade, H. "The mean value of a fuzzy number", Fuzzy Sets and Systems, 24(3), pp. 279-300 (1987).

42. Heilpern, S. "The expected value of a fuzzy number", Fuzzy Sets and Systems, 47(1), pp. 81-86 (1992).

43. Pishvaee, M.S., Rabbani, M., and Torabi, S.A. "A robust optimization approach to closed-loop supply chain network design under uncertainty", Applied Mathematical Modelling, 35(2), pp. 637-649 (2011).

44. Zhang, W. and Reimann, M. "A simple augmented $\epsilon$-constraint method for multi-objective mathematical integer programming problems", European Journal of Operational Research, 234(1), pp. 15-24 (2014). 
45. Mavrotas, G. "Effective implementation of the $\varepsilon$ constraint method in multi-objective mathematical programming problems", Applied Mathematics and Computation, 213(2), pp. 455-465 (2009).

\section{Biographies}

Hossein Gitinavard is currently $\mathrm{PhD}$ candidate at the Department of Industrial Engineering and Management Systems, Amirkabir University of Technology, Tehran, Iran. He received BSc and MSc degrees from the School of Industrial Engineering, University of Tehran and School of Industrial Engineering, Iran University of Science and Technology, respectively. His main research interests include fuzzy sets theory, multi-criteria decision-making under uncertainty, artificial neural networks, and applied operations research. He has published several papers in reputable journals and international conference proceedings.

Seyed Hassan Ghodsypour is a Professor at Amirkabir University of Technology, Tehran, Iran. His current research interests include multi-criteria decisionmaking, project management, portfolio management, and science and technology study. He has published numerous papers and book chapters in the aforementioned fields.

Mohsen Akbarpour Shirazi received his $\mathrm{PhD}$ degree in Industrial Engineering from Amirkabir University of Technology, Tehran, Iran, where he is now an Assistant Professor. His areas of research include supply chain planning, transportation, and modeling. $\mathrm{He}$ is the author and co-author of many technical papers in these fields. 